\title{
ESTUDO COMPARATIVO ENTRE O CONCRETO COM ADIÇÃO DE NANOSÍLICA E O \\ CONCRETO COM ADIÇÃO DE SÍLICA ATIVA EM SUSPENSÃO
}

COMPARATIVE STUDY BETWEEN CONCRETE WITH ADDITION OFNANOSYLIC AND

CONCRETE WITH ADDITION OF SILICON FUME IN SUSPENSION

Mônica Martins Schwartz ${ }^{11}$

Gabriela Cassol ${ }^{12}$

\section{RESUMO}

O concreto deve ser em seu estado endurecido resistente e ao mesmo tempo durável. Algumas adições minerais podem ser acrescentadas ao concreto com o objetivo de melhorar essas características, um exemplo de uma adição que comprova esses efeitos é a sílica ativa. Contudo, há alguns estudos sobre o uso de sílica ativa em escala nanométrica mais conhecida como nanosílica, mas estas pesquisas estão produzindo resultados variados e apesar de ser evidente o potencial deste tipo de adição não há um consenso sobre qual é o melhor percentual para se obter o melhor desempenho do concreto. Com isso, este trabalho busca responder à questão: Se compararmos a sílica ativa em suspensão e a nanosílica, qual delas apresentará maior resistência mecânica? Á vista disso, foi realizado um estudo de dosagem do concreto com adição de nanosílica e com adição de sílica ativa em suspensão, afim de se obter o melhor percentual de dosagem para cada um dos concretos e se fazer a comparação, foram realizados os ensaios do concreto no estado fresco e ensaios do concreto no estado endurecido, e por fim, analisados e avaliados os resultados encontrados.

Palavras-Chave: Concreto. Durabilidade. Nanosílica. Resistência à compressão. Sílica ativa.

\footnotetext{
${ }^{11}$ Acadêmica do Curso de Engenharia Civil da Universidade Alto Vale do Rio do Peixe (UNIARP). Email: monica.schwartz11@hotmail.com.

12 Professora Orientadora. Graduada em Engenharia Civil ,pela Universidade do Oeste de Santa Catarina (UNOESC), Mestrado em Engenharia Civil, pela Universidade Estadual Paulista "Julio de Mesquita Filho" (UNESP) campus de Ilha Solteira e docente do Curso de Engenharia Civil da Universidade Alto Vale do Rio do Peixe.
} 


\section{ABSTRACT}

The concrete should be in its sturdy and yet durable state. Some additions may be included in the concrete in order to improve these characteristics, an example of an 
addition that is subject to active silica. Hyphens, there are some studies on the use of active silicon nanometer scale, better known as nanosic, but the researches are produced in varied and despite the power to describe this type of additives, there is no consensus on what is the best percentage to obtain the best concrete performance. If we compare performance in an activity and a new routine, what is its greatest mechanical power? In view of this, a concrete dosage study was carried out with the addition of active data and comparisons, in order to obtain the best percentage of dosage for each of the concretes and to make a comparison, The fresh state and the tests of uncured concrete, and finally, the judgment and evaluation of the results found.

Keywords: Concrete. Nanosilica durability. Compressive strength. Silica fume.

\section{INTRODUÇÃO}

O concreto é o material mais utilizado na construção civil em todo mundo, ele está presente em grande parte das estruturas (MORAIS; LOPES, 2010). Com o advento da tecnologia, eles estão se tornando cada vez mais resistentes e duráveis. Sendo que nas últimas décadas, o uso de adições em concretos vem sendo amplamente pesquisado, com o propósito de melhorar o seu desempenho (SANTOS, 2016).

Uma dessas adições é a silica ativa que quando utilizada traz vantagens como aumento da resistência mecânica e química. Contudo, nota-se um interesse em partículas desta natureza em escala nanométrica, como a nanosílica. De acordo com Morais e Lopes (2010) pesquisas realizadas indicam que concretos produzidos com a adição de nanopartículas podem apresentar grandes ganhos de resistência a compressão.

Partindo disso, este trabalho tem como objetivo geral apresentar um estudo comparativo entre o concreto com adição de nanosílica e o concreto com adição de sílica ativa em suspensão. E consequentemente demonstrar qual dessas adições, apresentará maior resistência mecânica quando adicionada ao concreto.

O estudo experimental foi realizado no Laboratório de Materiais e Solos da Universidade Alto Vale do Rio do Peixe - UNIARP em Caçador. Primeiramente foi realizada a caracterização dos materiais que foram utilizados, em seguida, a dosagem do concreto com adição de nanosílica e do concreto com adição de sílica ativa em suspensão, após foi realizado ensaios no estado fresco e e endurecido do 
concreto e por fim, análise e avaliação dos resultados encontrados entre os teores utilizados de cada adição em relação ao concreto convencional.

\section{DESENVOLVIMENTO}

Este item apresenta uma revisão bibliográfica do concreto bem como das adições de nanosílica e sílica ativa em suspensão. Além de descrever os materiais e métodos que serão empregados.

\section{REFERENCIAL TEÓRICO}

Neste capítulo, serão abordados as definições e explanações sobre as adições de nanosílica e sílica ativa em suspensão, bem como suas características, e propriedades.

\section{Sílica Ativa}

A sílica ativa também é denominada microssílica, fumo de sílica ou fumo de sílica condensado. É um resíduo decorrente da produção de silício ou de ligas de ferrosilício, obtido a partir de quartzo de alto grau de pureza e de carvão em forno elétrico a arco submerso. A sílica ativa pertence à categoria dos materiais

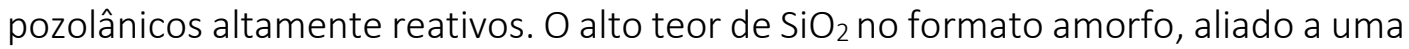
elevada finura, proporciona à substância uma altíssima reatividade com os produtos decorrentes da hidratação cimento, o que contribui para um melhor desempenho de concreto e argamassas (MORAES; LOPES, 2010).

Segundo a Tecnosil, (2013) a adição de teores entre 5 e 8\% de sílica ativa em relação ao peso do cimento melhora as características dos concretos e argamassas, tanto no estado fresco quanto no estado endurecido, proporcionando:
a) Baixa permeabilidade, porosidade, absorvidade;
b) Maior resistência mecânica;
c) Alta resistência a ambientes agressivos;
d) Aumenta a coesão;
e) Diminui a exsudação. 


\section{Nanosílica}

A nanosílica possui a mesma composição química que a sílica ativa. Entretanto, a principal diferença entre elas é o tamanho da partícula. O tamanho típico das partículas de sílica ativa está compreendido entre 200 e 1000 nm, enquanto o da nanosílica está entre 3 e 200 nm (TECNOSIL, 2013).

Segundo Silva (2016), as nanopartículas possuem uma grande área de superfície e elevada reatividade, quando comparadas com partículas com a mesma composição química e de tamanho maior. Esta característica, quando se fala em aplicação em misturas cimentícias, é responsável pela alteração de propriedades no estado fresco e endurecido, em comparação com as adições convencionais. Os grãos nanométricos participam de forma mais efetiva das reações pozolânicas, características da hidratação, resultando em novos materiais com desempenho superior.

\section{MATERIAIS E MÉTODOS}

Para atender o objetivo geral deste trabalho e tornar possível a realização do estudo comparativo entre o concreto acrescido de sílica ativa em suspensão e outro com nanosílica, foram dosados os materiais e moldados os corpos de prova no Laboratório de Materiais e Solos da Universidade Alto Vale do Rio do Peixe- UNIARP, logo, o rompimento dos corpos de prova foram realizados na empresa MineRocha Catarinense localizada na cidade de Caçador.

MATERIAIS

Para confecção do concreto e moldagem dos corpos de prova é necessária uma mistura de todos os seus componentes com a adição ou não de outros materiais. Logo abaixo demonstra-se os seguintes materiais que foram empregados:

\section{Cimento Portland}

O aglomerante utilizado neste trabalho na fabricação do concreto foi o cimento CP || Z - 32, segundo a NBR 11578 (ABNT, 1991), este tipo de cimento, é composto por limites fixos, com adição de material pozolânico de 6\% á 14\%, 94\% á 
$76 \%$ de componentes de clínquer e sulfatos de cálcio e até $10 \%$ de material carbonático. Podendo ter uma resistência de 25MPa, 32MPa ou 40MPa.

\section{Agregado miúdo natural}

Como agregado miúdo foi utilizada a areia proveniente da região de Porto União/SC, com massa especifica de $2,66 \mathrm{~g} / \mathrm{cm}^{3}$, massa unitária de $1,45 \mathrm{Kg} / \mathrm{dm}^{3}$ e com módulo de finura de 1,24 sendo classificado como uma areia fina.

\section{Agregado graúdo natural}

O agregado graúdo natural utilizado neste trabalho, possuia uma massa específica de $1,84 \mathrm{~g} / \mathrm{cm}^{3}$, massa unitaria de $1,45 \mathrm{Kg} / \mathrm{dm}^{3}$, diametro máximo de $12,50 \mathrm{~mm}$ e módulo de finura de 1,39 se classificando como brita 01 .

\section{Sílica ativa}

A sílica ativa que foi utilizada apresenta, conforme o fabricante, teor de $\mathrm{SiO}_{2}$ amorfo maior que $85 \%$, superfície específica de $20.000 \mathrm{~m}^{2} / \mathrm{kg}$, massa especifica de $2,220 \mathrm{~g} / \mathrm{cm}^{3}$ e formato de partícula esférico. O tamanho típico das partículas de sílica ativa está compreendido entre $200 \mathrm{~nm}$ e $1 \mu \mathrm{m}$. A massa unitária não densificada é inferior a $350 \mathrm{~kg} / \mathrm{m}^{3}$ e a massa unitária densificada superior a esse valor. A sílica ativa utilizada encontra-se na forma de suspensão em água, em proporção 50:50 em massa (TECNOSIL, 2013).

\section{Nanosílica}

A nanosílica que foi utilizada nesta pesquisa encontrava-se estabilizada ao aditivo químico superplastificante à base de policarboxilato, sendo suas partículas dispersas homogeneamente no mesmo e, portanto, possibilitando sua perfeita homogeneidade na massa do concreto no momento da mistura. O tamanho típico das partículas de nanosílica está compreendido entre 3 e 200 nm (TECNOSIL, 2013).

METODOLOGIA

A metodologia empregada nesse estudo foi experimental, descritiva, 
qualitativa e quantitativa e fundamentou-se em ensaios que foram seguidos de acordo com as Normas da ABNT, esses ensaios foram realizados no Laboratório de Materiais e Solos da Universidade Alto Vale do Rio do Peixe- UNIARP, afim de se obter os resultados para conclusão desse estudo.

\section{Método de dosagem}

Entre os métodos de dosagem experimental, o escolhido para este trabalho é conhecido como Método IPT/EPUSP, por ter sido desenvolvido no EPUSP/IPT (Escola Politécnica da Universidade de São Paulo/Instituto de Pesquisas Tecnológicas). Trata-se de uma forma de buscar curvas que expressam o comportamento dos materiais, e não um traço isolado para uma determinada resistência característica (HELENE; TERZIAN, 1992).

Para este presente trabalho, foram confeccionados os seguintes traços:

a) 1 traço de concreto convencional (C.V);

b) 1 traço de concreto com $5 \%$ de sílica ativa (C.S.A 5\%);

c) 1 traço de concreto com $8 \%$ de sílica ativa (C.S.A.8\%);

d) 1 traço de concreto com 0,45\% de nanosílica estabilizada (C.N 0,45\%);

e) 1 traço de concreto com 1,0\% de nanosílica estabilizada (C.N 1,0\%).

Para essa pesquisa foi definido um teor de argamassa de 69\%, portanto, a proporção do concreto de referência, em massa, considerada adequada foi 1:1,60:1,15 (cimento, areia e brita) e uma relação água/cimento de 0,46, é importante ressaltar que, para garantir a linha de comparação entre o concreto convencional, o concreto com sílica ativa em suspensão e o concreto com nanosílica estabilizada, procurou-se manter constante a relação água/cimento e o teor de argamassa entre os cinco tipos de concreto, ao se manter esse valor conseguimos garantir que toda a resistência adicional do concreto com sílica ativa ou nanosílica é proveniente dos benefícios desta adição mineral, e não da redução da relação água/cimento ou variação do teor de argamassa.

As proporções dos materiais utilizados nos traços desse estudo estão expressas na Tabela 01. 


\begin{tabular}{|c|c|c|c|c|c|c|}
\hline Materiais & & C.V & C.S.A $5 \%$ & C.S.A 8\% & C.N 0,45\% & C.N $1,0 \%$ \\
\hline \multirow{4}{*}{$\begin{array}{l}\text { Traço em } \\
\text { massa (35 } \\
\mathrm{kg} \text { ) }\end{array}$} & Sílica Ativa (kg) & & 0,4665 & 0,7464 & & \\
\hline & Cimento (kg) & 9,33 & 8,8635 & 8,5836 & 9,33 & 9,33 \\
\hline & Areia (kg) & 14,93 & 14,93 & 14,93 & 14,93 & 14,93 \\
\hline & Brita (kg) & 10,74 & 10,74 & 10,74 & 10,74 & 10,74 \\
\hline \multirow{3}{*}{ Aguá (L) } & Sílica ativa & & 0,4665 & 0,7464 & & \\
\hline & Adicionada & & 3,825 & 3,55 & & \\
\hline & Total & 4,30 & 4,30 & 4,30 & 4,30 & 4,30 \\
\hline \multicolumn{2}{|c|}{ Nanosílica estabilizada (kg) } & & & & 0,04199 & 0,0933 \\
\hline
\end{tabular}

Fonte: O próprio autor

\section{Ensaios do concreto}

Para a determinação da consistência do concreto no estado fresco foi realizado o ensaio descrito na NBR NM 67 (ABNT, 1998): Concreto - Determinação da consistência pelo abatimento do tronco de cone.

A massa específica do concreto no estado fresco foi determinada de acordo com a NBR 9833 (ABNT, 2009): Concreto fresco - Determinação da massa específica, do rendimento e do teor de ar pelo método gravimétrico.

Os corpos de prova utilizados nos ensaios do concreto endurecido foram os cilíndricos, que foram moldados de acordo com a NBR 5738 (ABNT, 2016): Concreto - Procedimento para moldagem e cura de corpos de prova. Sendo 9 para cada traço, que foram rompidos aos 7, 14 e 28 dias de idade. Após a moldagem os corpos de prova foram colocados em uma superficie livre de vibraçoes e cobertos nas suas primeiras $24 \mathrm{~h}$, por fim, foram colocados em um tanque com água, onde permaneceram até as datas de rompimento.

A resistência à compressão do concreto foi determinada pelo rompimento dos corpos de prova, segundo método expresso na NBR 5739 (ABNT, 2007): Concreto - Ensaios de compressão de corpos-de-prova cilíndricos.

\section{APRESENTAÇÃO, ANÁLISE DOS DADOS E RESULTADOS}

Serão apresentados e discutidos os resultados dos ensaios realizados, sendo expostos os resultados dos ensaios realizados no estado fresco e no estado 
endurecido do concreto, além das análises comparativas entre os diferentes tipos de concreto produzido.

\section{CONSISTÊNCIA}

Para verificação da trabalhabilidade do concreto no estado fresco, foi realizado o ensaio descrito na NBR NM 67 (ABNT, 1998). O gráfico 01 traz os valores de consistência obtidos para os traços de concreto em estudo.

Como pode ser observado no Grafico abaixo, os resultados obtidos para a trabalhabilidade da sílica ativa na presente pesquisa confirmaram aqueles observados por Morais e Lopes (2010) e Silva et al. (2016), pois foi possivel identificar que a sílica ativa, faz com que o concreto tenha um abatimento no slump-test menor em relação ao concreto convencional, perdendo a consistência, já os concretos produzidos com a adição de nanosílica apresentaram um Slump consideravelmente maior que os outros traços de concreto, devido ao fato de a nanosílica estar estabilizada em um aditivo quimico superplastificante, então, o aumento de trabalhabilidade se deve ao aditivo e não a nanosílica, se a nanosilica fosse adicionada em grãos secos ao concreto ou estabilizada apenas em água ela deveria apresentar um Slump menor que o concreto convencional.

Gráfico 4: Consistência dos traços de concreto

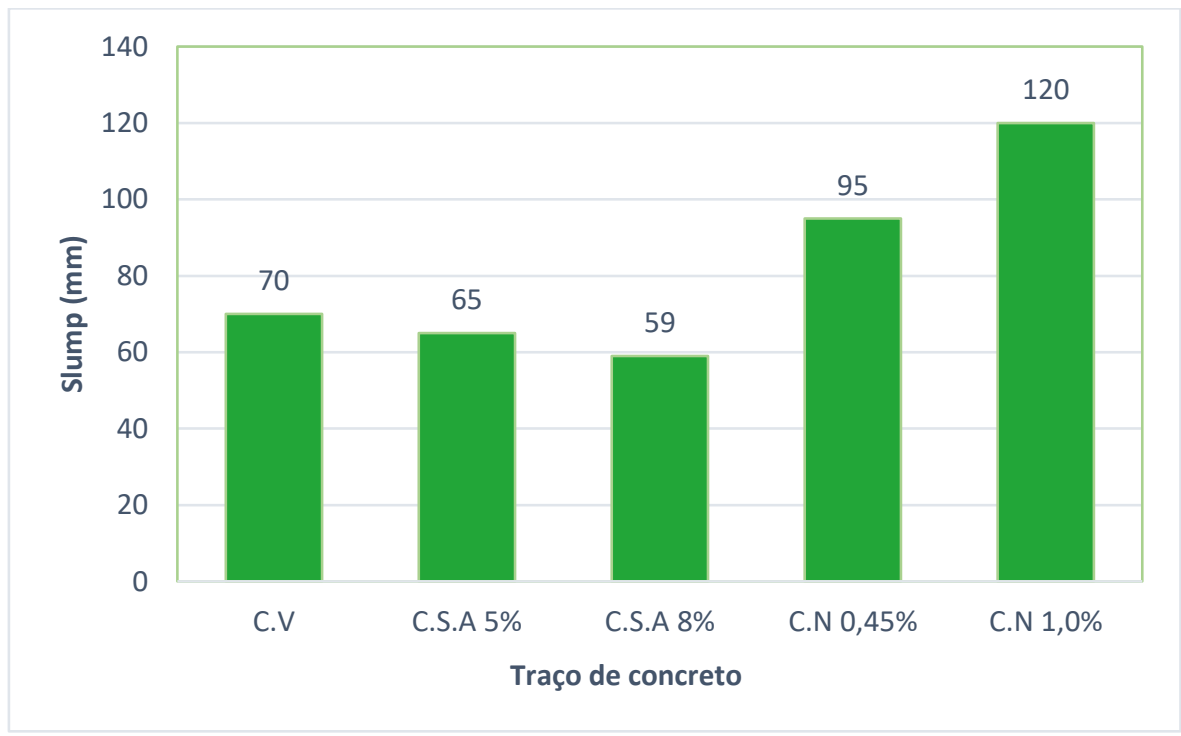

Fonte: O próprio autor

Ignis | Caçador | v.7 | n.2 | p. 80-94 | maio./ago. 2018 
MASSA ESPECÍFICA

Para determinação da massa específica do concreto, foi seguido o ensaio descrito na NBR NM 9833 (ABNT, 2009), logo em seguida, foi elaborado o Gráfico 02.

Gráfico 5: Massa específica dos traços de concreto

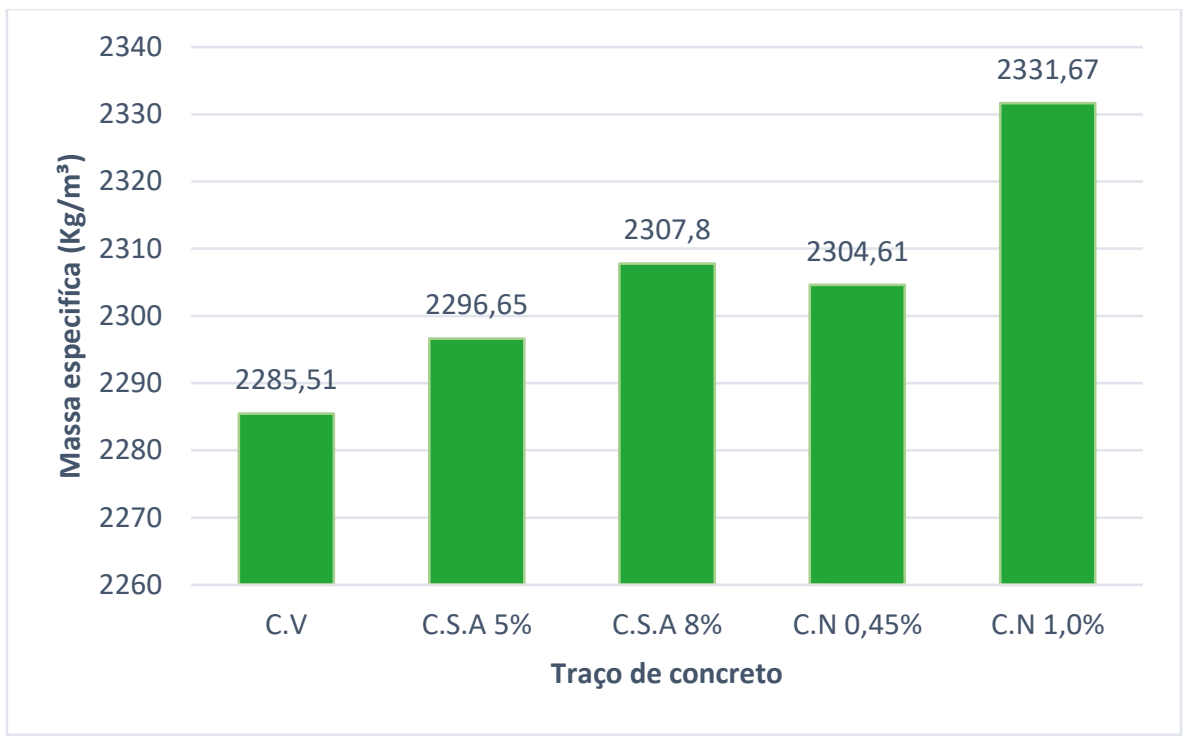

Fonte: O próprio autor

O concreto convencional (C.V) apresentou a menor massa específica entre os traços de concreto. O resultado obtido para a massa específica do concreto com sílica ativa (teores de 5\% e 8\%) comprovam aqueles observados por Tecnosil (2013) e Neto e Geyer (2017), pois a adição destes materiais proporcionou, redução na permeabilidade e porosidade se comparado ao concreto convencional.

O resultado obtido para a massa específica do concreto com nanosílica comprova o que foi observado nos estudos de Sobolev e Sanchez (2010, tradução nossa), por menor que seja a quantidade de nanosílica adicionada ao concreto mais densa será a mistura, reduzindo a permeabilidade e porosidade do concreto.

\section{RESISTÊNCIA À COMPRESSÃO}

Para determinação da resistência à compressão do concreto, foi seguido o procedimento descrito na NBR 5739 (ABNT, 2007), logo em seguida, com seus 
resultados foi elaborado o Gráfico 03.

Gráfico 6: Resistência à compressão dos traços de concreto

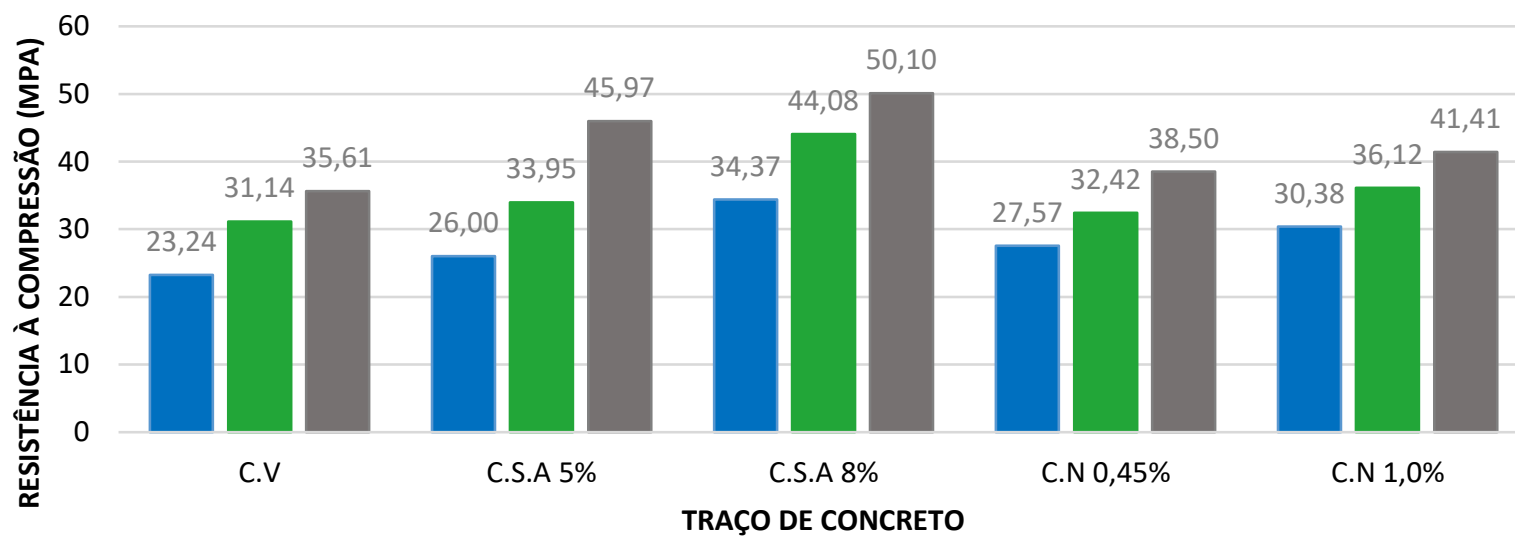

$\square$ dias $\square 14$ dias $\square 28$ dias

Fonte: O próprio autor

Conforme o Gráfico 3 acima o (C.V) foi o traço que apresentou menor resistência em todas as suas idades.

Analisando a Tabela de taxas de crescimento de resistências abaixo, observa-se que a taxa apresentada pelo traço (C.S.A 5\%) dos 7 a 28 dias de idades foi a maior, enquanto que as menores taxas foram apresentadas pelo concreto com adição de nanosilica (C.N 0,45\% e C.N 1,0\%).

Tabela 5: Taxa de crescimento de resistências

\begin{tabular}{llll}
\hline Traço & 7 a 14 dias & 14 a 28 dias & 7 a 28 dias \\
\hline C.V & $33,99 \%$ & $14,35 \%$ & $53,22 \%$ \\
\hline C.S.A 5 \% & $30,58 \%$ & $35,41 \%$ & $76,81 \%$ \\
\hline C.S.A 8 \% & $28,25 \%$ & $13,66 \%$ & $45,77 \%$ \\
\hline C.N 0,45 \% & $17,59 \%$ & $18,75 \%$ & $39,64 \%$ \\
\hline C.N 1,0 \% & $18,89 \%$ & $14,65 \%$ & $36,31 \%$ \\
\hline
\end{tabular}

Fonte: O próprio autor

Os resultados obtidos na pesquisa experimental confirmaram as expectativas quanto à adição de silica ativa no concreto, uma vez que notou-se um crescimento significativo entre as resistências. Comparado com o concreto convencional (C.V), o (C.S.A 8\%), foi responsável por um acréscimo de resistência aos 
28 dias de aproximadamente $40,69 \%$, além disso, entre as duas porcentagens de adições de sílica ativa nos 7 e 14 dias houve um acréscimo significativo de resistência do concreto com adição de 8\% (C.S.A 8\%) com relação ao concreto com 5\% (C.S.A $5 \%)$.

Os resultados obtidos para os concretos produzidos com nanosílica (C.N 0,45\%) e (C.N 1,0\%), em relação ao (C.V) foram satisfatórios, sendo que o (C.N 1,0\%) alcançou uma resistência de 41,41MPa (conforme Gráfico 5) e apresentou o maior acréscimo de resistência aos 28 dias para concretos com nanosílica, sendo responsável por um aumento de 16,29\% em relação ao (C.V) e 7,56\% com relação ao (C.N 0,45\%), já com relação ao (C.N 0,45\%) não houve um aumento significativo, cerca de $8,12 \%$ com relação ao (C.V).

Comparando os valores dos resultados experimentais entre o concreto com adição de sílica ativa (C.S.A 5\% e C.S.A 8\%) e o concreto com adição de nanosílica (C.N 0,45\% e C.N 1,0\%), nota-se que a adição de nanosílica não contribuiu positivamente para o crescimento da resistência à compressão do material, sendo que aos 28 dias de idade a resistência do (C.S.A 5\%) e (C.S.A 8\%) foram maiores que os outros traços.

Observando os valores dos resultados experimentais obtidos para cada traço de concreto, nota-se que a adição de sílica ativa melhorou as propriedades mecânicas do concreto endurecido, aumentando a sua resistência à compressão e confirmando os efeitos positivos da adição que já eram conhecidos.

A adição de nanosílica também contribui para o aumento da resistência do concreto convencional, contudo, em comparação com os traços produzidos com a adição de sílica ativa os resultados não foram satisfatórios. Esperava-se que a nanosílica pudesse causar um incremento ainda maior na resistência do concreto, ao refinar os poros da mistura.

\section{CONCLUSÃO}

Adições minerais de variadas fontes vêm sendo empregadas na indústria do concreto, trazendo vantagens em âmbitos técnicos, econômicos e ambientais. Hoje alguns autores julgam essencial o emprego de materiais pozolânicos a concretos que necessitem de propriedades específicas que são desejáveis em determinadas 
circunstâncias e nota-se um interesse crescente sobre o uso de partículas desta natureza, em escala nanométrica.

Sabe-se que o efeito da adição de sílica ativa em pó ao concreto promove melhorias em suas propriedades, particularmente em termos de durabilidade e resistência a compressão e que cada uma das diferentes formas de disponibilização da sílica ativa tem vantagens operacionais, e todas podem ser utilizadas com sucesso.

Quanto aos efeitos da nanossílica adicionada ao concreto, as pesquisas anteriores expõem que ainda não se conhece praticamente nada, e os poucos trabalhos realizados produziram resultados adversos sobre o uso desta adição e não conseguiram chegar a uma porcentagem ideal para se obter todo o seu potencial.

Com isso, o presente estudo tinha como objetivo comparar qual dessas adições é a mais benéfica para o concreto em termos de resistência à compressão. Para isso foi dosado um traço de concreto convencional, e a partir desse traço foram dosados dois traços de concreto com duas diferentes porcentagens de sílica ativa e dois traços de concreto com duas diferentes porcentagens de nanosílica.

Dos resultados obtidos durante essa pesquisa, confirmou-se todos os observados sobre a adição de sílica ativa, que em suas diferentes porcentagens substituindo a massa de cimento melhorou as propriedades mecânicas do concreto endurecido aumentando a sua resistência à compressão e confirmando os efeitos positivos ao concreto que já eram conhecidos.

Para o concreto com adição de duas diferentes porcentagens de nanossílica, esperava-se que esta adição pudesse causar um incremento ainda maior na resistência do concreto, ao se obter uma massa específica maior, ou seja, um concreto menos poroso e permeável, no entanto, a nanosílica da forma como foi utilizada apresentou um aumento de resistência se comparada ao concreto convencional, mas uma resistência menor com relação ao concreto com adição de sílica ativa.

Diante dos resultados, é presumível que a nanosílica, da forma como foi administrada ao concreto neste trabalho, apresentou pouca atividade pozolânica, cabe ressaltar que esses resultados foram obtidos para a nanosílica estabilizada em aditivo químico superplastificante e não foi possível utilizar porcentagens maiores, pois acarretavam em perda de consistência do concreto. 
Deste modo, conclui-se que a sílica ativa se mostrou a mais benéfica para este traço em estudo, mas cabe ressaltar que o emprego destas adições minerais ao concreto deve ser realizado após um estudo de custo $\mathrm{x}$ benefício que avalie a real contribuição desse material para a redução do custo total da edificação, já que é confirmado o aumento de resistência.

Sendo assim, fica como sugestões para trabalhos futuros realizar um estudo sobre o custo $\mathrm{x}$ benefício da sílica ativa em concretos. Seria interessante também realizar um estudo com nanosílica em pó, com maiores teores dessa adição ao concreto ou também utilizar ela em conjunto com outras adições até mesmo com a sílica ativa e avaliar as propriedades mecânicas desse concreto.

\section{REFERÊNCIAS}

ASSOCIAÇÃO BRASILEIRA DE NORMAS TÉCNICAS. NBR NM 67: Concreto-

Determinação da consistência pelo abatimento do tronco de cone. Rio de Janeiro, 1998.

ASSOCIAÇÃO BRASILEIRA DE NORMAS TÉCNICAS. NBR 5738: Concreto Procedimento para moldagem e cura de corpos de prova. Rio de Janeiro, 2016.

ASSOCIAÇÃO BRASILEIRA DE NORMAS TÉCNICAS. NBR 5739: Concreto- Ensaios de compressão de corpos-de-prova cilíndricos. Rio de Janeiro, 2007.

ASSOCIAÇÃO BRASILEIRA DE NORMAS TÉCNICAS. NBR 9833: Concreto fresco Determinação da massa especifica. Rio de Janeiro, 2009.

HELENE, Paulo; TERZIAN, Paulo. Manual de dosagem e controle do concreto. Brasília: Pini, 1992.

MORAIS, Nayara Queiros; LOPES, Rafaela Rocha. Análise da contribuição de adições de microssílica e nanosílica na resistência à compressão de concretos convencionais. 2010. 82 f. Monografia (Graduação) - Curso de Engenharia Civil. UFG, Universidade Federal de Goiás, Goiânia.

NETO, Tiago Ferreira Campos; GEYER, André Luiz Bortolacci. Efeitos do uso de aditivo com nanosílica em suspensão coloidal na consistência e resistência mecânica do concreto. REEC- Revista Eletrônica de Engenharia Civil, vol. 13, n. 2, p. 162-172, dezembro 2017. 
SANTOS, Thyala Anarelli Cunha e. Estudo da adição de polímero superabsorvente e de nano partículas de sílica para melhorar as propriedades de concretos de alta resistência. 2016. 166 f. Dissertação (Mestrado). Faculdade de Tecnologia. Universidade de Brasília, Brasília.

SILVA, Hygor Andrew da; FELIX, Elton José Pereira; MACHADO, Alexandre Cunha; GONÇALVES, Luzan Beiriz. Análise da influência de adição de sílica ativa na resistência à compressão em concretos. Ciências exatas e tecnologia, Maceió, vol. 3, n. 3, p. 41-54, novembro, 2016.

SOBOLEV, K., GUTIÉRREZ, M. F. How nanotechnology can change the concrete world: Part 2. American Ceramic Society Bulletin, Westerville, Ohio, EUA, v. 84, n. 11, p.16-19. 2005.

TECNOSIL. Sílica Ativa. Disponível em: <http://www.tecnosilbr.com.br/produtosaditivos-saco-soluvel-concreto/>. Acesso em: 26 março. 2018. 